\title{
Cardiopulmonary Resuscitation Training in Sport Universities: An Italian Survey
}

\author{
Andrea Scapigliati ${ }^{1}$, Saverio Giampaoli ${ }^{2}$, Alessia Marsili ${ }^{2}$, \\ Federica Valeriani ${ }^{2}$, Vincenzo Romano Spica ${ }^{2 *}$ \\ ${ }^{1}$ Catholic University of the Sacred Heart, Rome, Italy \\ ${ }^{2}$ University of Rome "Foro Italico", Rome, Italy \\ Email: "vincenzo.romanospica@uniroma4.it
}

Received December $17^{\text {th }}, 2012$; revised February $7^{\text {th }}, 2013$; accepted February $14^{\text {th }}, 2013$

Copyright (C) 2013 Andrea Scapigliati et al. This is an open access article distributed under the Creative Commons Attribution License, which permits unrestricted use, distribution, and reproduction in any medium, provided the original work is properly cited.

Background: Physical activity is associated to an increased risk of sudden cardiac death (SCD). Together with primary prevention, prompt recognition and early management of SCD are crucial in order to improve survival rate. During their duty, sport trainers and teachers can play a key role in secondary prevention of cardiac arrest provided they have received an appropriate training in Cardiopulmonary Resuscitation (CPR) during their curricular study. This is usually achieved through a Basic life Support and Defibrillation (BLS-D) Course which in Italy formally enables to Automated External Defibrillator (AED) use. Objective: To investigate the presence, the type and the diffusion of cardiopulmonary resuscitation training in Sport and Exercise Sciences Universities in Italy. Design: Descriptive survey research design was adopted for the study. Setting: The study sample consisted of 32 Italian Universities with Bachelor and Master-Level Degrees in Sport and Exercise Sciences. Methods: Teaching secretary or directly deans/ course presidents were contacted by email or telephone in order to collect information on the availability of BLS-D courses for Sport and Exercise Sciences students during the academic year 2010-2011. Results: The compliance to the survey has been $>93 \%$. Only a reduced number of the contacted Universities offered dedicated courses of Cardiopulmonary Resuscitation with license to Defibrillation according to current local regulation. Conclusion: The described situation shows a limit in the generation of a sport trainers' category highly specialized in cardiac and respiratory emergencies: only 6 Universities organize BLS-D training with official certification.

Keywords: Basic Life Support; Defibrillation; Cardiopulmonary Resuscitation; Sudden Cardiac Death; Cardiac Arrest; Sport; University; Public Health

\section{Introduction}

It is well recognized that regular physical activity reduces coronary heart disease events (Nam, 2011). However, exposure to vigorous exercise can increase the risk of sudden cardiac death (SCD) up to three times as higher in competitive athletes as in general population, acting as a trigger of cardiac arrest $(\mathrm{CA})$ on different age-related underling causes (American College of Sports Medicine \& American Heart Association, 2007; Thompson et al., 2007; Batra \& Balaji, 2012). Furthermore, sport practice can be associated with chest trauma (i.e., commotio cordis), other accidents such as drowning, or behaviors (drug abuse and doping) which are all potential causes of CA (Solberg et al., 2011). Our knowledge on epidemiology of sport-related CA is limited by difficult and discrepant data collection varying on geographical basis (Borjesson \& Pelliccia, 2009; Webner et al., 2012). From a European perspective, in the restricted area of Veneto Italian region, where a precious prospective registry of CA in young athletes ( $\leq 35$ years) is available, the SCD incidence was 3.6/100.000 participants per year (Corrado et al., 2006). In a recent France national survey based on ambulance

${ }^{*}$ Corresponding author. service data and media reports (susceptible of underreporting bias), the overall incidence of sport-related sudden death in the general population was 4.6 per million population per year, $90 \%$ during recreational sport activity and $6 \%$ in young competitive athletes (Marijon et al., 2011). In all studies an overwhelming male predominance was found. These data suggest that CAs in competitive and top athletes are not only the more visible aspect of a hidden but larger and more widespread phenomena. Recent episodes of CA during excellence sport competitions raised old questions on prevention and treatment of sport-related CA considering the large population which practice physical activity at any level. Mandatory medical screening as a tool of primary and secondary prevention has had a dramatic effect in the last three decades in decreasing SCD rate among competitive athletes in Italy (Corrado et al., 2009; Corrado et al., 2012). However, once CA has occurred for any reason (screening failure, unpredictable precipitating cause, fatal accident), bystander Cardiopulmonary Resuscitation (CPR) together with Automatic External Defibrillator (AED) use is recognized as the best intervention for early treatment of CA and is associated with higher survival rate compared with no early CPR, CPR alone without defibrillation and Emergency Medical 
System (EMS) arrival (Koster et al., 2010). Therefore, it is likely that public interventions aimed to a larger diffusion of CPR training and AED deployment in sport venues can act as an effective tertiary prevention strategy. A recent Italian law imposes the presence of AED in sport facilities (Republic of Italy, 2012). Since sport trainers and teachers can play a crucial role in prevention especially in recreational sport (where medical screening is far less implemented) and are likely to be among bystander rescuers in case of CA, a specific curricular education program on SCD prevention and treatment could be effective in reducing sport-related unexpected deaths.

In Italy, professional sport trainers and teachers have usually got a degree in Universities with Departments of Sport and Exercise Sciences (SES). In this context, dedicated courses of Basic Life Support and Defibrillation (BLS-D) with a specific focus on sport setting, can provide students with the ability to recognize and treat $\mathrm{CA}$ as well as altered level of consciousness and respiratory emergencies, with specific skill to operate an AED. In the present paper we investigated the diffusion of BLS-D training courses in Italian Universities with Bachelor and Master-Level Degrees in SES. The reported data are the result of a survey conducted in the Academic Year 2010-2011.

\section{Methods}

Thirty-two Italian Universities (Figure 1) with Bachelor and Master-Level Degrees in SES (13 in the north, 9 in the centre, and 10 in the south of the Country) had been identified through the Registry of the Italian Ministry of Education, Research and University and contacted electronically or by telephone in 2011 and 2012 for an interview. Questions were addressed to teaching secretary or directly to deans/course presidents. The interview was aimed to know if BLS-D courses dedicated to SES students were available in Academic Year 2010-2011 and, when present, if training was mandatory. Since Italian regulation currently allow the use of an AED by non-healthcare professionals (lay persons) only after a formal training with certification (valid for 1 year), a specific question addressed this information. The items of the survey are summarized in Table 1. BLS-D course was intended as including frontal lessons on SCD in sport, CA, CPR and AED use together with skill teaching on mannequins with $\mathrm{CA}$ simulation scenarios and AED training devices. For this kind of course 4 - 6 hours are traditionally requested with an instructor/students ratio of 1/5 - 6. Data collection was independently checked by two different researchers and where information was missing Universities were contacted again. If data interpretation was discrepant, discussion in presence of a third researcher allowed a final agreement. The collected data were processed and presented in this paper in a anonymous way.

\section{Results}

\section{Survey Categories}

Thirty Universities out of 32 included in the interview provided the requested information (compliance to the survey of $>93 \%$ ). According to the survey items (Table 1), the collected data were summarized in six categories:

1) MH (Mandatory \& Habilitation) Universities with mandatory BLS-D training and final certification for AED use in the Country;

2) $\mathrm{OH}$ (Optional \& Habilitation) Universities with optional

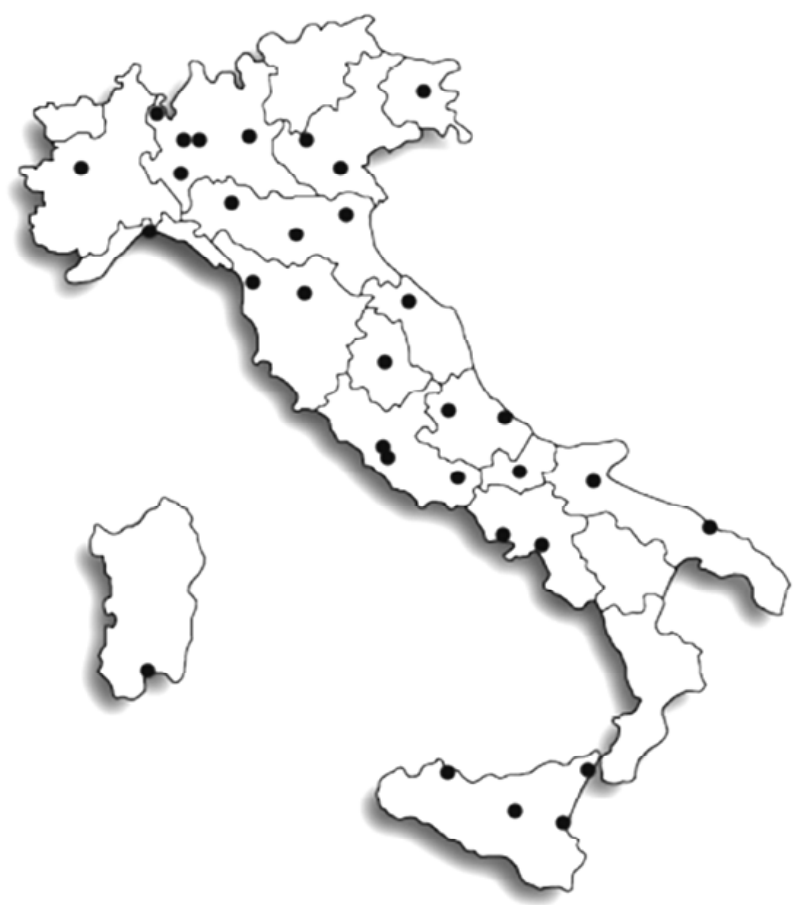

Figure 1.

Distribution on the national land of the universities involved in the survey.

Table 1.

Items of survey.

\begin{tabular}{cc}
\hline Questions & Answers \\
\hline BLS-D course training & Presence/Absence \\
Level of the degree involved & Bachelor/Master, both \\
Teachers involved & Relevant subject \\
Attendance & $\begin{array}{c}\text { Mandatory/Optional course, } \\
\text { number of students attending } \\
\text { AED use }\end{array}$ \\
Formal/Informal certification \\
Certification agency & Emergency Medical System \\
Other kind of training & (EMS)/Scientific organization \\
\end{tabular}

BLS-D training and final certification for AED use in the Country;

3) MW (Mandatory Without habilitation) Universities with mandatory BLS-D training but without final certification for AED use in the Country;

4) OW (Optional Without habilitation) Universities where the training was neither mandatory nor with certification;

5) GI (General Information) Universities were students received only general information on CPR without training;

6) N/A (Not Available) University without any kind of education on the subject.

\section{Survey Output}

As showed in Figure 2, the survey found that in the Academic Year 2010-2011, only one Italian University with Department of SES had mandatory training in BLS-D with final 


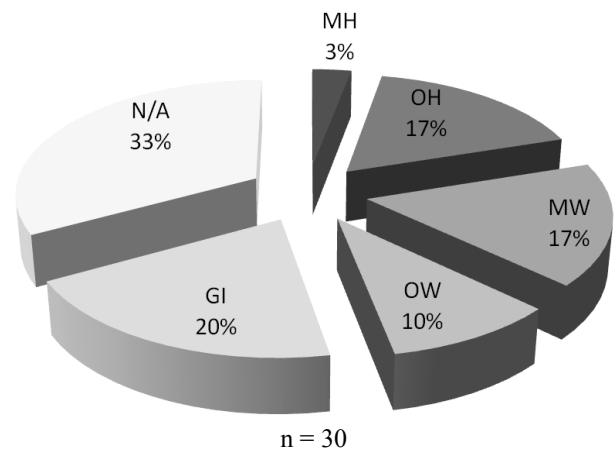

Figure 2.

Results of the survey by categories. MH (Mandatory \& Habilitation), (1/30). OH (Optional \& Habilitation), (5/30). MW (Mandatory Without habilitation), (5/30). OW (Optional Without habilitation), (3/30). GI (General Information), (6/30). N/A (Not Available), (10/ $30)$.

certification for AED use in the Country (1/30, 3\%). Five Universities $(5 / 30,17 \%)$ had a certified but optional BLS-D course involving a range of approximately 20 - 100 students per year. Overall Universities without AED use certification accounted for $27 \%$ of the total, $5 / 30$ with mandatory and $3 / 30$ with optional BLS-D Course respectively. The rest of the Universities responding to the survey provided general information on CPR as part of other courses $(6 / 30)$, or had no official lessons covering this issue (10/30). Among Universities with BLS-D courses and AED use certification, the average numbers of participating students was 36 (for this question the compliance of the survey was $33 \%$ ). The majority $(>62 \%)$ of Universities offering the BLS-D training organized courses both at the Bachelor and Master-Level Degree. All the University in the $\mathrm{MH}$ and $\mathrm{OH}$ categories were localized in the north and in centre of the Country (Figure 3). Where present, certification was provided by Emergency Medical System in 4 cases, from National Resuscitation Council in 2 cases.

\section{Discussion}

\section{The National Context}

The main result of the present survey is that only a minority of students attending Italian Universities with Department in SES are provided with formal training in CPR and AED use. Furthermore, no uniformity of teaching is present among Universities in the Country, reflecting a lack of common strategy. The presence of CPR and AED courses seems to depend more on local initiative more than on public health and teaching national planning. These findings can be explained primarily with the absence of a National regulation on education strategy and University teaching about this specific topic. This lack, together with discrepancies in local resources, can account for regional differences in BLS/AED training offer along the Country. However a deeper reason for this inadequate and non homogeneous frame is probably the poor general awareness about the crucial role of first responders in the treatment of CA victims.

\section{The Importance of Early Recognition of CA}

The well known concept of the Chain of Survival (the interdependent positive effect of a series of consecutive actions such

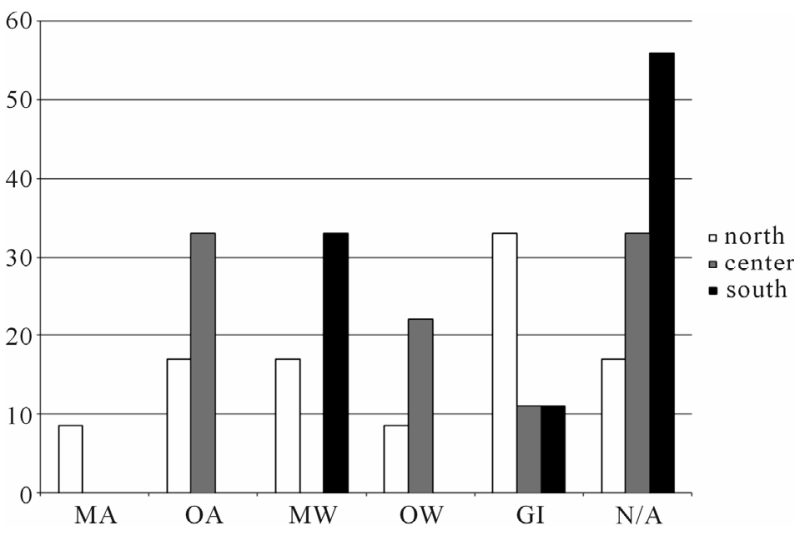

Figure 3.

Classification of survey results according to land localization of universities.

as Prevention, Early recognition and Call for help, Early CPR, Early Defibrillation, Post-resuscitation care) in the context of sport-related CA can rely on traditional healthcare professionals (i.e. physicians and EMS) mainly in the very first (i.e. prevention) and late links (i.e. the so called Advanced Life Support, ALS, usually restricted to the hospital phase of treatment) (Koster et al., 2010). The central links of the chain (i.e. early CPR and Defibrillation) are largely dependent on the first witnesses of CA, their willingness to step in rescue and their skill to perform correct actions. Available data in the specific sport context have proven how CA during sport activities is very often witnessed. As reported in Drezner et al. (2007) survey, 97\% of reported CA involving student athletes or older nonstudents involved in school-related sport activities were witnessed, 94\% received bystander CPR in about 1 minute from collapse and most of them received an AED shock after a short interval from collapse ( $<4$ minutes). Noteworthy, the first responder was a nontraditional health professional in the majority of cases (i.e., certified athletic trainers, coaches or teachers) when compared with school physicians and nurses, while EMS personnel were not on site at CA time in any case. In this series, overall survival to discharge was an outstanding $64 \%$ when compared with data related to out of hospital cardiac arrest in the general population (about 10\%) (Berdowski et al., 2010). In Marijon et al. (2011) study, bystander CPR, time from collapse to start CPR and defibrillation were the most important independent factors associated with survival. Furthermore, in a wider preventive strategy of SCD, non-traditionally health-related professionals can play a two-level role. Together with their role in tertiary prevention (i.e. treatment of CA once it has occurred), they can take part to the primary and secondary prevention (i.e. general and at risk population screening). Since neither ECG at rest nor exercise testing screening are mandatory in leisure-time sport activities, especially in middle aged/senior individual, trainers/ coaches/teachers can reinforce the first line screening with tutoring intervention, for instance with the administration of a validated physical evaluation questionnaire such as proposed by European Association of Cardiovascular Prevention and Rehabilitation (Borjesson, Urhausen et al., 2011).

\section{The Importance of Curricular Trainings}

Another reasons for poor diffusion of CPR training as found in this survey could be the lack of widespread and accepted 
recommendations on the specific topic. To work effectively, the Chain of Survival must be based on proper plans and preparedness. Skills acquisition in CPR is not for ever and frequent retraining is necessary to maintain proficiency as well as equipment (especially AED) needs periodic maintenance. While statements on emergency preparedness and SCD management in athletic facilities have been published in USA, a recent position stand from the Sports Cardiology section of the European Association of Cardiovascular Prevention and Rehabilitation (EACPR) aimed to fill a current gap about acute cardiovascular care at sport arenas in Europe (Drezner et al., 2007; Borjesson et al., 2011). A proper curricular training for SES Universities should take in account the elements suggested in these statements, enabling students to have an active role in elaborating and implementing emergency plans in sport venues where they could work. Specific features of sport-related CA should be covered as well, such as how to deal with frequent seizure-like activity and pulse/respiration presence (in $50 \%$ and $57 \%$ of cases respectively in Drezner et al. (2007) study), a description of commotio cordis and general information on pediatric CA, foreign body airway obstruction treatment and rescue lateral positioning of the victim. In our Institution we aimed to cover with all these issues through a Course on Medical Emergencies at Sport Venues including a formal BLS-D Course with AED use certification. The none uniform distribution of BLS-D courses, as showed in the results of the survey presented in this paper, can clearly discriminate some regions (for example south and islands in Italy) where students did not have the opportunity to obtain a valid training in CRP inside their academic curriculum studiorum. The described situation shows a limit in the generation of a sport trainers category highly specialized in cardiac and respiratory emergencies. This can be an important safety issue for sport activities performed in minor leagues, where the sport trainer/coach is generally the only reference for athletes. The institution of mandatory and official courses in CRP inside university teaching programs is highly auspicial, in order to guarantee a wide distribution of sport trainers and assistants able to face many medical emergencies. Considering the need to have a formal certification to operate an AED in Italy, a more effective cooperation with regional EMS and Scientific Societies such as National Resuscitation Council seems urgent. Most sport-related, sudden cardiac deaths occur in public sports areas (track, gymnasium), where others athletes or insiders are present: unfortunately only a reduced percentage of these witnesses are potentially life-saving cardiopulmonary resuscitation operators. The role of the bystanders in initiating resuscitation should be valorized, starting from the bystanders par excellence in sport facilities: coaches, trainers and assistant athletic trainers. Project focused on CPR training and placement of automated external defibrillators are thought to be both efficacious and cost-effective, and for this reason a standardized, uniform and ubiquitous teaching program should be provided to sport students (Berger et al., 2004; Salib et al., 2005). Unfortunately only a reduced number of Italian Universities with Bachelor and Master-Level Degrees in sport and exercise sciences offers dedicated courses for BLS-D with final national authorization/ license.

\section{Acknowledgements}

This work has been supported by the scientific collaboration with the IRC Italian Resuscitation Council and the scientific committee of ICSPS2013 (www.icsps-rome2013.it). Authors thanks Dr. Elena Scaramucci (Sant'Andrea Hospital, Rome, Italy) for the collaborative discussion useful comments and criticism.

\section{REFERENCES}

American College of Sports Medicine, American Heart Association (2007). Exercise and acute cardiovascular events: Placing the risks into perspective. Medicine and Science in Sports and Exercise, 39, 886-897. doi:10.1249/mss.0b013e3180574e0e

Batra, A. S., \& Balaji S. (2012). Prevalence and spectrum diseases predisposing to sudden cardiac death: Are they the same for both the athlete and the nonathlete? Pediatric Cardiology, 33, 379-386. doi:10.1007/s00246-012-0159-1

Berdowski, J., Berg, R. A., Tijssen, J. G., \& Koster, R. W. (2010). Global incidences of out-of-hospital cardiac arrest and survival rates: Systematic review of 67 prospective studies. Resuscitation, 81, 14791487. doi:10.1016/j.resuscitation.2010.08.006

Berger, S., Whitstone, B. N., Frisbee, S. J., Miner, J. T., Dhala, A., Pirrallo, R. G. et al. (2004). Cost effectiveness of Project ADAM: A project to prevent sudden cardiac death in high school students. $\mathrm{Pe}$ diatric Cardiology, 25, 660-667. doi:10.1007/s00246-003-0668-Z

Borjesson, M., \& Pelliccia, A. (2009). Incidence and aetiology of sudden cardiac death in young athletes: An international perspective. British Journal of Sports Medicine, 43, 644-648. doi:10.1136/bjsm.2008.054718

Borjesson, M., Serratosa, L., Carre, F., Corrado, D., Drezner, J., Dugmore, D.L. et al. (2011). Consensus document regarding cardiovascular safety at sports arenas: Position stand from the European Association of Cardiovascular Prevention and Rehabilitation (EACPR), section of Sports Cardiology. European Heart Journal, 32, 2119 2124. doi:10.1093/eurheartj/ehr178

Borjesson, M., Urhausen, A., Kouidi, E., Dugmore, D., Sharma, S., Halle, M. et al. (2011). Cardiovascular evaluation of middle-aged/ senior individuals engaged in leisure-time sport activities: Position stand from the sections of exercise physiology and sports cardiology of the European Association of Cardiovascular Prevention and Rehabilitation. European Journal of Cardiovascular Prevention and Rehabilitation, 18, 446-458. doi:10.1097/HJR.0b013e32833bo969

Corrado, D., Basso, C., Pavei, A., Michieli, P., Schiavon, M., \& Thiene, G. (2006). Trends in sudden cardiovascular death in young competitive athletes after implementation of a preparticipation screening program. JAMA: The Journal of the American Medical Association, 296, 1593-1601. doi:10.1001/jama.296.13.1593

Corrado, D., Basso, C., \& Thiene, G. (2012). Sudden cardiac death in athletes: What is the role of screening? Current Opinion in Cardiology, 27, 41-48. doi:10.1097/HCO.0b013e32834dc4cb

Corrado, D., Migliore, F., Bevilacqua, M., Basso, C., \& Thiene, G. (2009). Sudden cardiac death in athletes: Can it be prevented by screening? Herz, 34, 259-266. doi:10.1007/s00059-009-3236-3

Drezner, J. A., Courson, R. W., Roberts, W. O., Mosesso Jr., V. N., Link, M. S., \& Maron, B. J. (2007). Inter-association task force recommendations on emergency preparedness and management of sudden cardiac arrest in high school and college athletic programs: A consensus statement. Clinical Journal of Sport Medicine, 17, 87-103. doi:10.1097/JSM.0b013e3180415466

Koster, R. W., Baubin, M. A., Bossaert, L. L., Caballero, A., Cassan, P., Castren, M. et al. (2010). European Resuscitation Council Guidelines for Resuscitation 2010 Section 2. Adult basic life support and use of automated external defibrillators. Resuscitation, 81, 1277 1292. doi:10.1016/j.resuscitation.2010.08.009

Republic of Italy (2012). Law 189, 08.nov.2012. Conversion into law, with amendments, of decree-law of 13 September 2012, n. 158, containing urgent measures to promote the development of the country by a high level of health protection.

Marijon, E., Tafflet, M., Celermajer, D. S., Dumas, F., Perier, M. C., Mustafic, H. et al. (2011). Sports-related sudden death in the general population. Circulation, 124, 672-681. 


\section{A. SCAPIGLIATI ET AL.}

doi:10.1161/CIRCULATIONAHA.110.008979

Nam, G. B. (2011). Exercise, heart and health. Korean Circulation Journal, 41, 113-121. doi:10.4070/kcj.2011.41.3.113

Salib, E. A., Cyran, S. E., Cilley, R. E., Maron, B. J., Thomas, \& N. J. (2005). Efficacy of bystander cardiopulmonary resuscitation and outof-hospital automated external defibrillation as lifesaving therapy in commotio cordis. The Journal of Pediatrics, 147, 863-866. doi:10.1016/i.jpeds.2005.07.041

Solberg, E. E., Embra, B. I., Borjesson, M., Herlitz, J., \& Corrado, D. (2011). Commotio cordis-Under-recognized in Europe? A case report and review. European Journal of Cardiovascular Prevention and Rehabilitation, 18, 378-383. doi:10.1177/1741826710389363
Thompson, P. D., Franklin, B. A., Balady, G. J., Blair, S. N., Corrado, D., Estes, N. A. et al. (2007). Exercise and acute cardiovascular events placing the risks into perspective: a scientific statement from the American Heart Association Council on Nutrition, Physical Activity, and Metabolism and the Council on Clinical Cardiology. Circulation, 115, 2358-2368.

doi:10.1161/CIRCULATIONAHA.107.181485

Webner, D., Duprey, K. M., Drezner, J. A., Cronholm, P., \& Roberts, W. O. (2012). Sudden cardiac arrest and death in United States Marathons. Medicine and Science in Sports and Exercise, 44, 18431845 . 